Editorial

\title{
Cohesion in the Local Context: Reconciling the Territorial, Economic and Social Dimensions
}

\author{
Hans Thor Andersen ${ }^{1, *}$, Mia Arp Fallov ${ }^{2}$, Anja Jørgensen ${ }^{2}$, Maja de Neergaard ${ }^{1}$ and Rikke Skovgaard Nielsen ${ }^{1}$ \\ ${ }^{1}$ Department of the Built Environment, Aalborg University, 9220 Aalborg, Denmark; E-Mails: hta@sbi.aau.dk (H.T.A.), \\ mlsdn@build.aau.dk (M.D.N.), rsn@sbi.aau.dk (R.S.N.) \\ 2 Department of Sociology and Social Work, Aalborg University, 9220 Aalborg, Denmark; \\ E-Mails: fallov@socsci.aau.dk (M.A.F.), anjaj@socsci.aau.dk (A.J.) \\ * Corresponding author
}

Submitted: 14 October 2020 | Published: 3 December 2020

\begin{abstract}
This brief editorial introduces a set of articles dealing with territorial challenges in Europe. The EU and the member states have put attention to a silent, but growing issue of inequality: The spatial disparities are in several member states considered able to provide wider political tensions and challenges. Consequently, the EU has launched a research theme in its framework programme Horizon 2020 to cope with such matter. Most of the papers in this issue have their origin in the Horizon COHSMO project "Inequality, Urbanization and Territorial Cohesion. Developing the European Social Model of Economic Growth and Democratic Capacity." While social or economic inequalities are recognized as a social problem, spatial disparities are forgotten or ignored. However, territorial inequalities do boost social and economic differences and add to growing tensions and contradictions in many cases. Coping with such challenges is a difficult matter; most European countries have had programmes aiming at rebalancing regional inequalities for many years. Despite major investments in public services, infrastructure, education and culture, as well as targeted support for private investors, businesses raising employment opportunities and so on. However, the success in terms of growing population and employment has been limited. Instead, endogenous structures and relations receive more attention; in particularly local capacity to generate solutions and means to promote economic and social development. This ability strongly links to the concept of collective efficacy, i.e., a joint understanding and capability to organize and execute actions of mutual benefit.
\end{abstract}

\section{Keywords}

European regional development; inequality; inter-scalar relations; local development; social cohesion; spatial justice; territorial cohesion; territorial government

\begin{abstract}
Issue
This editorial is part of the issue "Cohesion in the Local Context: Reconciling the Territorial, Economic and Social Dimensions," edited by Anja Jørgensen (Aalborg University, Denmark), Mia Arp Fallov (Aalborg University, Denmark), Rikke Skovgaard Nielsen (Aalborg University, Denmark), Hans Thor Andersen (Aalborg University, Denmark) and Maja de Neergaard (Aalborg University, Denmark).
\end{abstract}

(C) 2020 by the authors; licensee Cogitatio (Lisbon, Portugal). This article is licensed under a Creative Commons Attribution 4.0 International License (CC BY).

\section{Introduction}

It is evident that places differ in terms of qualities and opportunities. Those born in backward regions face more obstacles on average compared to children living on the sunny side. However, life chances for the individual do sometimes differ considerably between neighbour- hoods within the same city, just as villages and smaller towns may offer very unequal opportunities despite being located in the same region. The spatial impact is visible as marked differences in employment, education, income, health, living conditions and so on. Social relations and spatial structures influence even the personality of individuals. 
Yet, in the best of all worlds, the place of birth or living should have as little impact as possible on socioeconomic chances and public policies should be in place to lessen such inequalities. This is obviously not the case; a simple check on life expectancy reveals surprisingly big differences both between countries and regions, but also between neighbourhoods, as well as between social classes. A strong spatial variation is similarly shown concerning health status. Moreover, after a long period of catching-up for most of the disadvantaged regions, inequalities among regions in Europe are now growing again.

The geographies of economic, social and political development change as new industries and technologies, social demands and opportunities, cultural, religious relations and so on replace older structures and relations. Such changes have accelerated over the last decades and produced new lines of division and contradiction; former successful regions have faced decline for half a century now without significant progress while previously-backward regions suddenly appear as new, successful centres for high-tech manufacturing. Whilst some regions experience rising conflicts, rising unemployment and depopulation, others seem to have found a 'magic formula,' a positive relationship between collective efficacy and governance that allows them to benefit from territorial capital.

Several mega-trends have emerged over a short period; globalisation, which has removed or at least reduced barriers for a free flow of capital and commodities, sometimes also for labour, has reframed conditions for local politics and economics and thus for key components of living opportunities at the national, regional or local level. Moreover, globalisation has also reshaped media, culture and education in many cases. Migration has increased in number and made many metropolises truly multi-cultural, which further speeds up processes of globalisation. In parallel to this, the ageing of developed countries is rapidly producing new challenges in terms of growing needs for care and health systems, the search for alternative ways of financing welfare services than via taxation. Many Western countries now require more labour; a need that only migration can solve.

Industrial and economic changes together with social and cultural shifts have recently produced a period of fast urbanisation. Urbanisation has, first of all, fuelled the growth of larger cities. On the other side, rural districts, in many cases suffer from depopulation and consequently of stagnation, sometimes of decline. A key effect is a challenged territorial cohesion.

Most European countries have for decades attempted to better integrate various parts of their territory to benefit from the advantages of a coherent and fairly structured nation-state. A combination of marked territorial disparities and simultaneous social and political dissatisfaction may enhance disintegration and produce new oppositions.

\section{Territorial Cohesion-A Contested Concept}

Territorial cohesion may simply be understood as a conceptual development of the European Spatial Development Perspective (ESDP) by adding a dimension of spatial justice (Davoudi, 2005). This adds a clear normative element to the spatial policies of the European Union. Moreover, territorial cohesion appears as a replacement of the ESDP by connecting a spatial perspective to the European social model. There are numerous definitions of territorial cohesion, but the core issue is that the uncertainty related to the concept permits the concept to allow a wide range of interpretations. Thus, despite very different opinions and priorities, many stakeholders and politicians can see themselves on board. Territorial cohesion is an abstract concept, which does not challenge European agreement: The political disagreement does not arrive before translation into practical policymaking; however, this challenge is transferred to lower levels of government, i.e., national or most often the regional government. Territorial cohesion has a strong positive connotation; it does not include ideological U-turns or seriously challenge actual regional inequalities. It just expresses the wish of fairness between all territories; who would be against the noble aim of spatial justice or coherent territories? The question remains by which means, and at what cost.

Territorial cohesion is a policy term, which has entered policy spheres at almost all scales and concerning several dimensions: The European Union has at times attempted to challenge the hegemonic position of the nation-state and national scale as a default reference for politics, the economy and social and cultural relations. By considering social scales other than the national level, first of all regions, but also local scales as well as cross-national scales as relevant for policy implementation, the European Union has launched new arenas for cooperation and policymaking. Yet, these 'new' or reactivated tiers of government were, and remain, weak compared to national levels. Nevertheless, analysis and facts show substantial similarities between and across member states, in general since national governments formulate or promote the vast majority of policies. Only when the European Union co-finances cross-border initiatives, e.g., the INTERREG-programmes, there have been attempts to solve problems together and across national borders.

While the diagnosis is clear, the correct treatment remains unknown. Various governments have attempted several methods over time: Regional policies have changed from financial support and infrastructure investments, exemption from restrictions concerning building codes, environmental or labour market issues, to job training, transfer of public institutions in order to increase employment, and setting up of educational and cultural institutions. Unfortunately, the overall picture seems quite stable; few depressed regions have managed to catch up or develop into thriving and prosperous regions. 
The OECD (2019) delivers an interesting approach in Rural Policy 3.0; it concludes that policies based on subsidies and protection are unable to counteract depopulation and the decline of service provision. Instead, a radical shift was launched in $\mathbf{2 0 0 6}$ with a focus on the competitiveness of rural areas (OECD, 2006). The new policy includes a shift from only economic objectives to encompassing social and environmental issues, a dismissal of the rural-urban dichotomy in favour of a nuanced view on the relationship between rural and urban areas and finally a shift from government alone to the inclusion of private business as well as civil society. Former emphasis on competitiveness is replaced by well-being in three dimensions: economy, society and environment. The value of local embedded structures and relations may explain the successes or failures of many localities. Consequently, more soft relations, local cultures and traditions, have gained importance in policies for territorial cohesion. This understanding is running through several of the articles in this volume.

\section{The Thematic Issue}

This thematic issue is generally divided in three parts. The first part delivers an overall understanding of territorial cohesion, its first logical question being what territorial cohesion is and how we should understand it. The second part presents examples of territorial cohesion in different types of areas and related to various scales. The articles here draw on empirical data from the Horizon 2020-funded programme COHSMO. The third part of the issue consists of two articles: one on the methodological challenges when researching territorial cohesion and the other aiming to bridge the gap between academic debate and policymaking.

Part one of this thematic issue presents the substance of an oft-used concept: territorial cohesion. It is, as claimed by many, a concept easy to feel comfortable with since everyone can understand it from their point of view. Yet, in an academic debate, concepts have to be firmer and more stringent. How can we measure degrees of territorial cohesion unless we have a strict definition? Weckroth and Moisio (2020) provides an overview of how the concept is defined, framed and justified in European Union policies. They base their overview on the analysis of official speeches by European Union commissioners responsible for regional policies. The focus is particularly on the meaning of territorial cohesion and its justification. Boczy, Cefalo, Parma, and Skovgaard Nielsen (2020) deliver an analysis of larger cities as places for the global knowledge economy and the challenges that follow rising competitiveness and inequalities. While the narrow perspective in most development strategies is on economic performance, larger cities have to consider social inequality as a potential source for future tension. In practice, strategies that can recognise and balance different concerns have better chances to remain cohesive and competitive. Artelaris and Mavrommatis (2020) examine territorial cohesion as a policy narrative and the diverse narrative structure of the concept. The rhetoric of cohesion links to sub-narratives, perhaps in order to produce a balance between competitiveness and social well-being.

We continue on with four cases of how territorial cohesion is treated in practice at different scales and localities. Boczy and Cordini (2020) focus on cognitive assets in regional or spatial policies and investigate the mixed assets of cognitive relations and material structures concerning planning discourses. They study three types of localities - urban, suburban and rural-in two member states (Austria and Italy) in order to make intra-regional as well as inter-regional comparisons. Jørgensen, Fallov, Corsado-Diaz, and Atkinson (2020) present a comparative analysis of two peripheral and mostly rural localities in Denmark and the United Kingdom. Their aim is to investigate endogenous development and social cohesion in two different, national settings, which face similar challenges of de-population trends and lacking economic growth. The comparison of the two cases highlight the importance of both formal and informal forms of local leadership, and that collective efficacy might be a useful way to analyse the 'soft dimensions' of leadership for rural territorial development. Bucaitè-Vilkè and Krukowska (2020) compare suburban governance in Polish and Lithuanian municipalities: They find that the two governments have a different composition of vertical and horizontal networks, of how local stakeholders perform and in particularly collective action. Aksztejn (2020) aims at downscaling spatial inequalities as well as the concept of territorial cohesion to the municipal level. Her approach is to criticise European understanding; this understanding directs attention and funding towards the regional level, whilst inequalities are present also at the local level and intermunicipal differences are much larger than between regions. Aksztejn does not focus on income, education or employment, but on access to selected public services and perceived inequalities among local stakeholders.

Finally, Atkinson and Pacchi (2020) notice the separate treatment of three forms of cohesion: social, economic and territorial. The missing incorporation of the three dimensions into one coherent policy loses potential gains of relevance for an efficient spatial policy. The authors admit that academic criticism of these concepts has not made life easier for EU policymakers. However, the policymakers have worked with concepts like 'functional area,' which seem clarifying at first glance, but later on, only provide further frustrations whenever attempts are made to delineate a region. de Neergaard, Fallov, Skovgaard Nielsen, and Jørgensen (2020) struggle in their article with a similar problem: If we cannot use administrative delimited regions as the basis for comparisons since they seldom reflect a meaningful entity sharing costs and benefits, responsibility between population and decision-makers, businesses, then comparative analysis become wishful ambitions. Leaning towards an 
idea presented by Doreen Massey, the authors suggest using a 'conjunctural approach,' i.e., examine and understand similar dynamics within and between places to compare the incomparable elements. This offers the possibility to dive deeper into an understanding of dimensions of territorial cohesion by investigating how embedded structures, place histories, collective 'imaginaries' of place, and potential coalitions or conflictual relations are articulated together.

Altogether, the nine articles analyse and discuss territorial cohesion from an abstract to a very down-to-earth level that is sure to enlighten the reader. Together they offer insights into how localities matter in relation to a cross-European discussion of territorial cohesion and inequality. However, the last word on territorial cohesion is not yet on paper.

\section{Acknowledgments}

The main part of the contributions results from the Horizon 2020 project COHSMO (grant agreement No 727058) "Inequality, Urbanization and Territorial Cohesion. Developing the European Social Model of Economic Growth and Democratic Capacity." The project includes seven partners across Europe-England, Lithuania, Italy, Austria, Poland, Greece and Denmarkand runs from 2017-2021.

\section{Conflict of Interests}

The authors declare no conflict of interests.

\section{References}

Aksztejn, W. (2020). Local territorial cohesion: Perception of spatial inequalities in access to public services in Polish case-study municipalities. Social Inclusion, 8(4), 253-264.

\section{About the Authors}

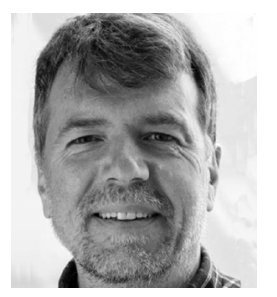

Hans Thor Andersen (PhD Social Geography and Urban Politics) is Research Director at Department of the Built Environment, Aalborg University. His has earlier researched housing policies and regional development strategies. Hans Thor Andersen is also Project Coordinator for the EU Horizon 2020 COHSMO project "Inequality, Urbanization and Territorial Cohesion. Developing the European Social Model of Economic Growth and Democratic Capacity."

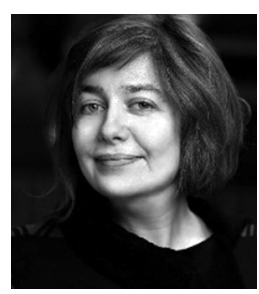

Mia Arp Fallov (PhD Sociology) is Associate Professor of Social Integration and Social Policy Strategies in Department of Sociology and Social Work at Aalborg University, Denmark. Her research covers territorial cohesion, urban planning welfare policy, urban sociology, social theory and strategies to improve inclusion. Recently she is working on the EU Horizon 2020 COHSMO project "Inequality, Urbanization and Territorial Cohesion. Developing the European Social Model of Economic Growth and Democratic Capacity." sion as a policy narrative: From economic competitiveness to 'smart' growth and beyond. Social Inclusion, 8(4), 208-217.

Atkinson, R., \& Pacchi, C. (2020). In search of territorial cohesion: An elusive and imagined notion. Social Inclusion, 8(4), 265-276.

Boczy, T., Cefalo, R., Parma, A., \& Skovgaard Nielsen, R. (2020). Positioning the urban in the global knowledge economy: Increasing competitiveness or inequality. Social Inclusion, 8(4), 194-207.

Boczy, T., \& Cordini, M. M. (2020). Narratives of territorial cohesion and economic growth: A comparative study. Social Inclusion, 8(4), 218-228.

ucaitè-Vilkè, J., \& Krukowska, J. (2020). Rethinking subof two municipalities in Poland and Lithuania. Social Inclusion, 8(4), 242-252.

Davoudi, S. (2005): Understanding territorial cohesion. Planning, Practice and Research, 20(4), 433-441. son, R. (2020). Rural cohesion: Collective efficacy and leadership in the territorial governance of inclusion.

e Neergaard, M., Fallov, M. A., Skovgaard Nielsen, R., \& Jørgensen, A. (2020). Contexts and interconnecs: A conjunctural approach to territorial cohesion.

OECD. (2006). The new rural paradigm: Policies and governance. Paris: OECD.

Paris: OECD. Retrieved from https://www.oecd.org/ rural/rural-development-conference/documents/ Rural-3.0-Policy-Highlights.pdf

Weckroth, M., \& Moisio, S. (2020). Territorial cohesion of what and why? The challenge of spatial justice for EU's cohesion policy. Social Inclusion, 8(4), 183-193.
Artelaris, P., \& Mavrommatis, G. (2020). Territorial coheSocial Inclusion, 8(4), 229-241. 


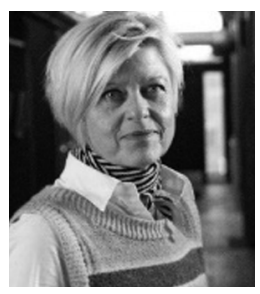

Anja Jørgensen (PhD) is Professor of Urban Sociology and Head of the research group SocMap (www.socmap.aau.dk) in the Department of Sociology and Social Work at Aalborg University, Denmark. She has conducted a wide range of research-projects within urban sociology, territorial cohesion, local communities and local social integration. Recently she is working on the EU Horizon 2020 COHSMO project "Inequality, Urbanization and Territorial Cohesion. Developing the European Social Model of Economic Growth and Democratic Capacity."

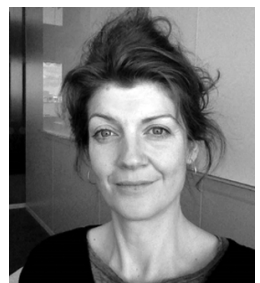

Maja de Neergaard (PhD) is a Researcher at Department of the Built Environment, Aalborg University, Denmark. Her research interests are urban geography and culture, urban/regional restructuring processes, inhabitation practices, and theory of the relations between humans, nature and technology. Presently, she is working on the Horizon 2020 COHSMO project "Inequality, Urbanization and Territorial Cohesion. Developing the European Social Model of Economic Growth and Democratic Capacity."

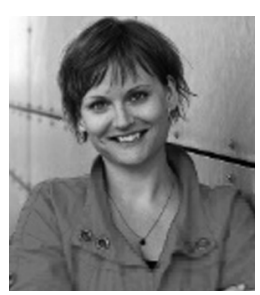

Rikke Skovgaard Nielsen is a Senior Researcher of Department of the Built Environment, Aalborg University, Denmark, and coordinates the Master Program "City, Housing and Settlement Patterns." Rikke's research is centred on inequality, deprived neighbourhoods, diversity, segregation and regeneration plans. Of major international research projects, she has taken part in the NORFACE project NODES, the EU FP7 project DIVERCITIES and currently the Horizon 2020 project COHSMO. Recent publications include Governance Arrangements Targeting Diversity in Europe: How New Public Management Impacts Working with Social Cohesion (https://doi.org/10.1080/02723638.2018.1511190). 